\title{
DETERMINING THE CLIMATE RELEVANCE OF REFUSE-DERIVED FUELS - VALIDITY OF LITERATURE-DERIVED VALUES IN COMPARISON TO ANALYSIS-DERIVED VALUES
}

\author{
Therese Schwarzboeck ${ }^{1}$, Philipp Aschenbrenner ${ }^{1}$, Sarah Muehlbacher ${ }^{1}$, Soenke Szidat ${ }^{2}$, \\ Stefan Spacek ${ }^{1}$ and Johann Fellner ${ }^{1}$ \\ ${ }^{1}$ Institute for Water Quality and Resource Management, TU Wien, Karlsplatz 13, 1040 Vienna, Austria \\ ${ }^{2}$ Laboratory for the Analysis of Radiocarbon with AMS (LARA), Department of Chemistry and Biochemistry \& Oeschger Centre for \\ Climate Change Research, University of Bern, Freiestrasse 3, 3012 Bern, Switzerland
}

Article Info:

Received:

23 January 2018

Revised:

15 May 2018

Accepted:

25 June 2018

Available online:

30 June 2018

Keywords:

Refuse derived fuels

Balance method

Biomass content

Fossil carbon

Elemental composition

Manual sorting

\begin{abstract}
The adapted Balance Method (aBM) represents a cost efficient method for determining the fossil share in solid refuse-derived fuels (RDF). The method requires data on the elemental composition of the RDF on water-and-ash-free basis $\left(\right.$ TOX $\left._{\mathrm{RDF}}\right)$ and on the elemental composition of biogenic and fossil organic matter on water-andash-free basis present in the RDF (TOX ${ }_{\text {Bio }}$ and TOX ${ }_{\mathrm{Fos}}$ ). TOX $\mathrm{BDio}_{\mathrm{Bio}}$ and TOX $\mathrm{Fos}_{\mathrm{Fos}}$ generally need to be defined only once (e.g., before a routine application). After these data are known, only $\mathrm{TOX}_{\mathrm{RDF}}$ needs to be determined analytically for any RDF sample in order to apply the aBM. As TOX $_{\text {Bio }}$ and TOX $\mathrm{F}_{\text {Fos }}$ are crucial input parameter for the aBM, the presented paper aims to assess the most suitable and practical way for their reliable determination. Within this study, 6 different solid RDFs are investigated and the aBM is applied, whereby the suitability of literature values is compared to own analysis data for $\mathrm{TOX}_{\mathrm{Bio}}$ and $\mathrm{TOX}_{\mathrm{Fos}}$. The potential utilization of literature data could save the initial workload when applying the aBM and could make the method even more economical and practical compared to other methods. Altogether, seven aBM results are compared utilizing seven different methods for generating input values of $\mathrm{TOX}_{\mathrm{Bio}}$ and $\mathrm{TOX}_{\mathrm{Fos}}$ : using generic values, literature values only, analyses results only, or combinations of literature and analyses data. The study results suggest that the usage of analysis data together with information from literature is the best option to derive reliable input data $\left(\mathrm{TOX}_{\mathrm{Bio}}\right.$ and TOX $\mathrm{Fos}_{\text {fos }}$ ) for the aBM (mean deviation from standardized methods of below $2 \%$ ). The findings further suggest that there is a typical composition of the biogenic and fossil organic matter present in RDFs produced out of commercial and industrial waste. Thus, the initial workload for conducting RDF-specific analyses could be significantly reduced when some more data about different types of RDFs are collected (e.g in a database).
\end{abstract}

\section{INTRODUCTION}

Within the European Union, in 2012 already 34\% of primary energy carriers in cement kilns are substituted by mixed wastes and refuse-derived fuels (RDF). In Austria an average substitution rate of $75 \%$ is reported (VÖZ, 2015). The utilization of alternative fuels in energy-intensive industry branches is a means to reduce the exploitation of natural resources, reduce costs and to lower fossil carbon dioxide emissions (Aranda Usón et al., 2013; Pomberger and Sarc, 2014). For the appraisal on the fossil $\mathrm{CO}_{2}$-savings (and therewith connected economic savings for emission certificates), it is required to know on the one hand the carbon content originating from materials of fossil origin in the RDF and on the other hand the overall calorific value of the RDF. Both depend, among others (e.g., water content), on the shares of fossil and of biogenic materials. In solid RDFs fossil materials comprise mainly plastics and synthetic textiles; biogenic materials could be paper, natural fibers, wood, etc. The shares of the compounds in solid RDFs are usually not known and may vary significantly depending on the material used for RDF production. The material used is usually pre-treated municipal solid waste (MSW), commercial waste (CW) and industrial waste (IW). The composition thus, strongly depends on the input material and hence, on the collection and sorting schemes, and also on local industries. Further, the shares of fossil and biogenic materials present in the RDF are decided by 
the production process (processing units used) which is designed based on the target application (e.g., cement kiln, waste-to-energy plant) (Lorber et al., 2012; Nasrullah et al., 2014a,b; Nasrullah et al., 2015; Sarc et al., 2014).

To distinguish between $\mathrm{CO}_{2}$-emissions originating from fossil (climate relevant) and biogenic (carbon neutral) sources in solid RDFs, different methods are available: The Selective Dissolution Method (SDM), the Radiocarbon Method $\left({ }^{14} \mathrm{C}\right.$-method), the Manual Sorting (MS), and the Balance Method (BM). The former three are described in the standard for solid recovered fuels EN 15440:2011; the Balance Method has recently been published in the standard ISO 18466:2016. The methods all have critical limitations, such as high and hardly quantifiable uncertainties (SDM, MS), high workload (MS), high chemical demand (SDM), high analytical costs ( ${ }^{14} \mathrm{C}$-method) and solely post-combustion application (BM) (Jones et al., 2013; Schwarzböck et al., 2018; Schwarzböck et al., 2016b; Staber et al., 2008).

A practical, and cost-efficient approach to determine the climate-relevant (fossil) $\mathrm{CO}_{2}$-emissions from the utilization of solid RDF is provided by the so-called "adapted Balance Method" (aBM) (Fellner et al., 2011). This method combines data about the elemental composition of the RDF - TOX ${ }_{\text {RDF }}$ (C, H, N, S, O-content on water-and-ash free basis) - with the RDF-specific elemental composition of pure biogenic and pure fossil organic matter - TOX ${ }_{\text {Bio }}$ and $\operatorname{TOX}_{\text {Fos }}$ (C, H, N, S, O-content on water-and-ash free basis). By setting up mass balances for each element, the fossil carbon content in the RDF can be derived. The aBM has recently been demonstrated to produce robust results which are in good agreement with the radiocarbon method (usually regarded as reference method) (Schwarzböck et al., 2016a; Schwarzböck et al., 2016b).

The necessary data for the application of the aBM are $\mathrm{TOX}_{\mathrm{RDF}}$ TOX $_{\mathrm{Bio}}$ and TOX $\mathrm{Fos}_{\text {. The determination of TOX }}$. always requires elemental analysis in the laboratory. To validate the method, in previous works TOX $_{\text {Bio }}$ and TOX Fos $_{\text {have }}$ also been analytically appraised for each investigated RDF (initially). This initial investigation requires sorting of the RDF into its different compounds (paper, wood, plastics, etc.) and elemental analyses of each compound. In order to reduce the initial workload and costs, available data on the elemental composition of different materials present in the RDF could be used. Potential sources for these data are literature values, information from industries or theoretical considerations (e.g., theoretical chemical structure of cellulose, polyethylene, etc.).

For example in Fellner et al. (2011) data for $\operatorname{TOX}_{\mathrm{Bio}}$ and TOX $_{\text {Fos }}$ in RDF are provided, which were collected from various literature sources and production statistics in Austria. Monte Carlo simulations were applied to derive $\operatorname{TOX}_{\mathrm{Bio}}$ and TOX $_{\text {Fos }}$ which should be valid for RDF. However, it is not clear if these values are generally valid for RDF or maybe only for a certain type of RDF (e.g., for RDF produced out of MSW).

In Schwarzböck et al. (2017) it is shown, that the probable range of TOX $\mathrm{Bio}_{\mathrm{Bio}}$ only varies to a minor extend as the different compounds (paper, wood, garden waste, natural fibers) have a very similar chemical composition on wa-

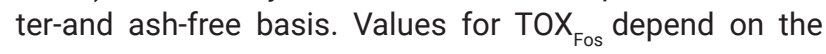

shares of the different polymers. Schwarzböck et al. (2017) assume that polyethylene and polypropylene represent the major part (around 80wt\%) in mixed wastes which are fed into waste-to-energy plants in Austria. Kost (2001) conducted an extensive study on the characterization of waste compounds and collected literature data and own analysis data on the fractional and elemental composition of MSW.

Due to varying origins of the RDF production material (MSW, CW, IW), the composition of RDF may vary, depending on the characteristics of the waste catchment area (urban, rural, types of industry and businesses, etc.) and waste collection and treatment schemes.

The objective of the present paper is to evaluate the suitability of literature values for the application of the aBM in comparison to RDF-specific values (derived via extensive analyses) to determine the fossil carbon content in RDF. Therefore, the following parameter necessary to derive $\mathrm{TOX}_{\mathrm{Bio}}$ and $\mathrm{TOX}_{\mathrm{Fos}}$ in the RDF are varied, either based on literature or own analyses:

- Fossil and biogenic mass share in each compound $\mathrm{k}$ of the RDF (e.g., fossil share in composite materials); $\mathrm{x}_{\mathrm{mF}, \mathrm{k}^{\prime}}, \mathrm{x}_{\mathrm{mB}, \mathrm{k}}$

- Chemical composition of fossil and biogenic matter in each sorted compound $\mathrm{k}$; $\mathrm{TOX}_{\mathrm{k}}^{\mathrm{Fos}}$ and $\mathrm{TOX}_{\mathrm{k}}^{\text {Bio }}$

Additionally the so generated results are compared to

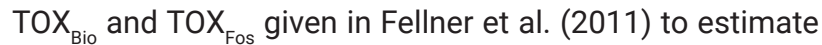
the validity of the previously collected literature data.

\section{MATERIAL AND METHODS}

\subsection{Adapted Balance Method (aBM)}

The aBM combines data about the elemental composition of the RDF (carbon, hydrogen, oxygen, nitrogen, and sulphur-content on water-and-ash free basis) with the theoretical composition of pure biogenic and fossil organic matter present in the RDF $(\mathrm{C}, \mathrm{H}, \mathrm{O}, \mathrm{N}$, S-content on waterand-ash free basis) - see Figure 1 . For each element $(C, H$, $\mathrm{O}, \mathrm{N}, \mathrm{S}$ ) a mass balance equation is set up which contains the unknown mass fractions of fossil $\left(m_{F}\right)$ and biogenic matter $\left(m_{B}\right)$. As illustrated in Figure 1, the elemental composition of the biogenic and fossil matter is significantly different. This allows the 5 balance equations to be solved by data reconciliation and the mass fractions of fossil and biogenic matter to be derived. By inserting the results $\left(m_{B}\right.$, $m_{F}$ ) into the carbon balance, the fraction of fossil carbon as percentage of the total carbon can be determined.

The aBM requires the following input data:

1. Elemental composition of the water-and-ash-free RDF $\left(\mathrm{TOX}_{\mathrm{RDF}}\right)$ : Determination by CHNSO-analyses and ash content determination

2. Information on the elemental composition of the waterand-ash-free biogenic and fossil organic matter present in the RDF $\left(\mathrm{TOX}_{\mathrm{Bio}}, \mathrm{TOX}_{\mathrm{Fos}}\right)$. The following options are available:

Collection of necessary information from literature

- Determination by manual sorting together with CHNSO-analyses and ash content determination of the sorted compounds 


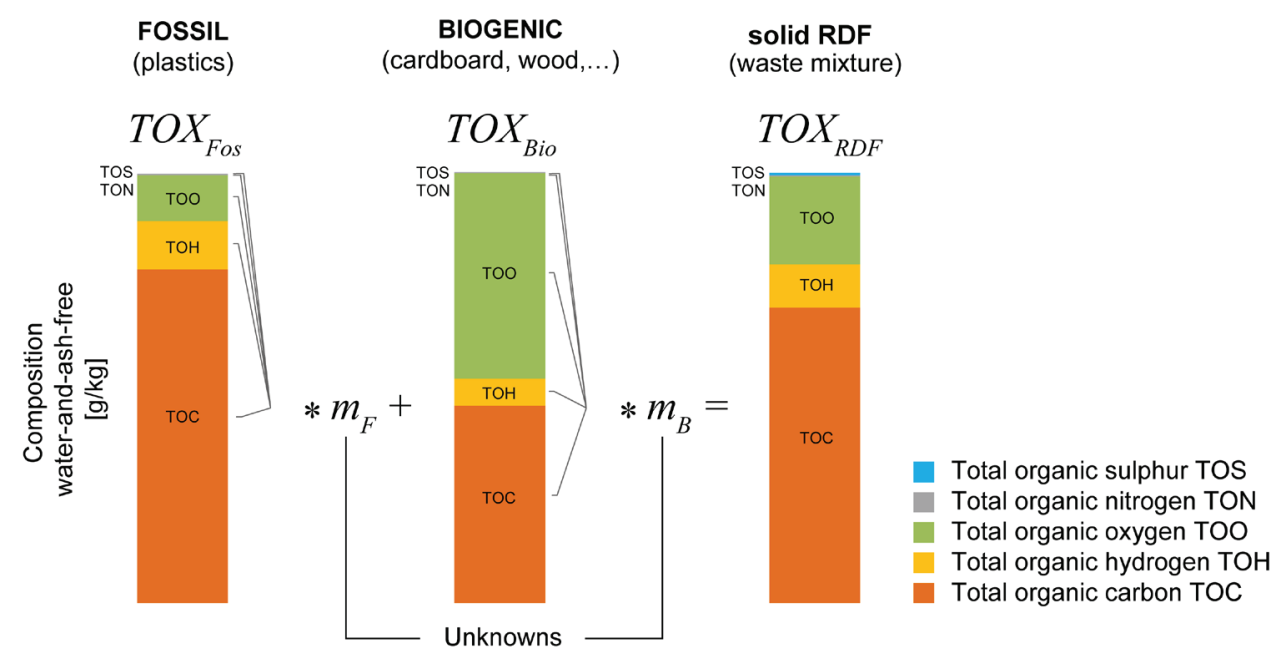

Mass share of FOSSIL and BIOGENIC matter

FIGURE 1: Schematic illustration of the adapted Balance Method, showing the relation between the elemental composition of the water-andash-free biogenic and fossil organic matter present in the RDF (TOX $\left.{ }_{\mathrm{Bio}}, \mathrm{TOX}_{\mathrm{Fos}}\right)$, the elemental composition of the water-and-ash-free RDF $\left(\mathrm{TOX}_{\mathrm{RDF}}\right)$ and the respective mass shares of fossil and biogenic matter $(\mathrm{mF}$ and $\mathrm{mB})$, which are unknown and determined by the aBM.

- Combination of information from literature and analyses

Within this study, the different options to gather the necessary information for the aBM are compared. The different variants used are described in Table 2.

\subsection{Samples and sample preparation}

Six different solid refuse-derived fuels (RDF) are subject of the study. Table 1 lists the different samples and their origin and indicates which methods to determine the fossil share, besides the aBM, are applied to the samples.

As only a few hundred milligrams of sample are necessary for the CHNSO-elemental analysis, the samples are comminuted down to a grain size of below $0.2 \mathrm{~mm}$. The sample preparation is carried out in agreement with EN 15413:2011 and based on findings of Schwarzböck et al., 2016a. Two cutting mills (Essa CM 1000 and Retsch SM 2000), an ultracentrifugal mill (Retsch ZM 200), and a cryogenic mixer mill (Cryomill, Retsch) are used to produce representative analysis samples. Additionally riffle divider and rotary divider are used to reduce the sample mass between the grinding steps.

\subsection{Analyses}

\subsubsection{CHNSO-elemental analysis}

CHNSO elemental analysis is used to derive the elemental composition in the water-and-ash-free RDF samples, which is necessary in order to apply the aBM.

The water free (dried at $105^{\circ} \mathrm{C}$ for 24 hours) analysis samples undergo a CHNSO-elemental analysis using an Elementar Vario Macro instrument (for CHNS-analysis) and an Elementar Vario El instrument (for O-analysis, based on pyrolysis) (Elementar Analysensysteme $\mathrm{GmbH}$, Hanau, Germany). At a combustion temperature of $1,150^{\circ} \mathrm{C}$, the total carbon (TC), total hydrogen (TH), total nitrogen (TN), total sulphur (TS), and total oxygen (TO) content is determined according to EN 15407:2011. Additionally the ash content of each test sample is determined according to EN 15403:2011 and analyzed for its elemental composition to appraise the total inorganic content of $\mathrm{C}, \mathrm{H}, \mathrm{N}, \mathrm{S}$, and $\mathrm{O}$.

TABLE 1: Investigated refuse-derived fuels and number of samples analyzed

\begin{tabular}{|c|c|c|c|c|}
\hline Name & Origin / type of RDF & No of samples $\mathbf{N}$ & Sorting analysis & ${ }^{14} \mathrm{C}$-method ${ }^{1}$ \\
\hline Paper Reject & Residues of paper \& board industry & 15 & $\checkmark$ & $\checkmark$ \\
\hline RDF MSW+C\&I & $\begin{array}{l}\text { RDF prepared from pre-processed municipal solid waste } \\
\text { and commercial \& industrial waste (RDF production } \\
\text { plant A) }\end{array}$ & 8 & $\checkmark$ & $\checkmark$ \\
\hline RDF C\&I (1) & $\begin{array}{l}\text { RDF prepared from mainly commercial \& industrial } \\
\text { waste (RDF production plant A) }\end{array}$ & 8 & $\checkmark$ & $\checkmark$ \\
\hline RDF C\&I (2) & $\begin{array}{l}\text { RDF prepared from mainly commercial \& industrial } \\
\text { waste (RDF production plant B) }\end{array}$ & 3 & $\checkmark$ & - \\
\hline RDF C\&I (3) & $\begin{array}{l}\text { RDF prepared from mainly commercial \& industrial } \\
\text { waste (RDF production plant B) }\end{array}$ & 2 & $\checkmark$ & - \\
\hline RDF C\&I (4) & $\begin{array}{l}\text { RDF prepared from mainly commercial \& industrial } \\
\text { waste (RDF production plant B) }\end{array}$ & 3 & $\checkmark$ & - \\
\hline
\end{tabular}

${ }^{1}$... tick indicates that Radiocarbon analyses $\left({ }^{14} \mathrm{C}\right.$-method) are additionally conducted according to EN 15440:2011 for selected samples to support the findings by $\mathrm{aBM}$ and sorting. 
Five measurements per sample, each of them comprising $40 \mathrm{mg}$ of sample material, are carried out for $\mathrm{C}, \mathrm{H}, \mathrm{N}$, and $\mathrm{S}$. For the analysis of 0 , sample specimens of only 4 to $6 \mathrm{mg}$ are used and 7 measurements per sample are conducted.

The measured values are converted according to Formula (1) in order to determine the elemental composition on a water-and-ash-free reference base.

$T O X=\frac{T X-T I X * A}{(1-A)}$

TOX: total organic fraction of $\mathrm{C}, \mathrm{H}, \mathrm{O}, \mathrm{N}$ and $\mathrm{S}$ in the waterand-ash-free sample $\left[\mathrm{g} / \mathrm{kg}_{\text {waf] }}\right.$

TX: total fraction of $\mathrm{C}, \mathrm{H}, \mathrm{O}, \mathrm{N}$ and $\mathrm{S}$ in the water free sample $\left[\mathrm{g} / \mathrm{kg}_{\mathrm{wf}}\right.$

TIX: total fraction of $\mathrm{C}, \mathrm{H}, \mathrm{O}, \mathrm{N}$, and $\mathrm{S}$ in the water free ash (inorganic) $\left[\mathrm{g} / \mathrm{kg}_{\mathrm{wf}}\right]$

$A$ : ash content $\left[\mathrm{kg} / \mathrm{kg}_{\mathrm{wf}}\right]$

The thereby obtained values for total organic carbon (TOC), total organic hydrogen ( $\mathrm{TOH})$, total organic nitrogen (TON), total organic sulphur (TOS), and total organic oxygen represent the input data required for the adapted Balance Method.

2.3.2 Radiocarbon method $\left({ }^{14} \mathrm{C}\right.$-method) to determine the share of fossil carbon present in RDF

The Radiocarbon method $\left({ }^{14} \mathrm{C}\right.$-method) is based on the distinctly different concentration of ${ }^{14} \mathrm{C}$ isotope in fossil carbon sources (where ${ }^{14} \mathrm{C}$ is completely decayed) and in modern (biogenic) carbon sources, which exhibit in a first approximation the current ${ }^{14} \mathrm{C}$ atmospheric levels. Thus, the ${ }^{14} \mathrm{C}$-concentration in the emitted $\mathrm{CO}_{2}$ when a waste mixture is combusted is directly proportional to the fraction of biogenic carbon in the combusted sample (Mohn et al., 2008). However, owing to anthropogenic activities the background level of ${ }^{14} \mathrm{C}$ levels in the atmosphere was altered, which complicates the calculation as it requires reference basis to be recalculated for each grow year of biomass (Fellner and Rechberger, 2009). Yet, the method is regarded as very reliable method for the determination of the biomass content in secondary fuels as it has the lowest analytical uncertainty (accelerator mass spectrometry $<1 \%$ relative; Mohn et al., 2008).

Within the presented study, the ${ }^{14} \mathrm{C}$-method is applied according to EN 15440:2011 utilizing accelerator mass spectrometry (AMS). Around $10 \mathrm{mg}$ of 16 RDF samples at a grain size of $<0.2 \mathrm{~mm}$ are combusted at $900^{\circ} \mathrm{C}$ and the carbon isotope ${ }^{14} \mathrm{C}$ is separated from the stable carbon isotopes ${ }^{12} \mathrm{C}$ and ${ }^{13} \mathrm{C}$ before the mass analysis (for details see Szidat et al., 2014). The biogenic content in the sample is given as percent of modern carbon, allowing the fossil carbon to be calculated. A fossil mass share cannot be provided by this method.

\subsubsection{Manual sorting}

In order to determine the elemental composition of biogenic and fossil organic matter in the RDFs (see section 2.4), manual sorting analyses are conducted. Samples of each RDF are sorted into the following compounds:

\section{- Paper}

\section{Wood}

Plastics

Composites \& unrecognizable materials

Textiles

- Rubber - only further considered for RDF C\&I (B3); for other RDFs share is below $0.8 w t \%$

- Fine fraction (around $<1-2 \mathrm{~cm}$ )

- Metals and inert materials - not further considered as this fraction is neither considered biogenic nor fossil

300 to $500 \mathrm{~g}$ (for Paper Reject up to $3.000 \mathrm{~g}$ ) per sample are sorted. For Paper Reject and RDF from producer A RDF MSW+C\&I and RDF C\&I (1) - a part of the fine fraction is further sorted into the above listed compounds. The so determined mass shares of the fine fraction are accounted for in order to estimate the total share of each compound in the RDF.

The results of the sorting analysis are on the one hand used to determine the respective input parameter of the $\mathrm{aBM}$, and on the other hand the outcomes are utilized to estimate the overall share of the fossil mass present in the RDF. The latter are finally compared to the results generated by the aBM. However, some deviations from the procedure given in EN 15440:2011 for the manual sorting method are considered in order to generate more reliable results: the fine fraction is partly further sorted and the fossil and biogenic share in each compound are estimated analytically instead of relying on the information given in the standard. Yet, the manual sorting method is connected with high uncertainties, especially when high shares of mixed compounds (fine fraction, composites, textiles) are present in the RDF.

\subsection{Determination of the elemental composition of biogenic and fossil organic matter present in RDF (TOX Bio, TOX $_{\text {Fos }}$ )}

Besides the elemental composition of the water-andash-free RDF ( $\mathrm{TOX}_{\mathrm{RDF}}$ ), the application of the aBM requires information on the elemental composition of the waterand-ash-free biogenic and fossil organic matter (TOX ${ }_{\text {Bio' }}$ TOX $_{\text {Fos }}$ ). Seven different alternatives (Variants) are chosen in order to derive these data sets (description see Table 2).

The following assumptions are applied for all variants:

1. No analyses are available for the composition of fossil (synthetic) and biogenic textiles (cotton, wool) TOX $_{\text {textile }}$ Fos and TOX texile $^{\text {Bio }}$ Thus, for all applied variants, the chemical composition of textiles is based on data published by Kost (2001) and on theoretical considerations.

2. The biogenic share in the composite \& unrecognizable materials represents paper and the fossil share represents plastics (all on water-and-ash-free basis).

The first variant (Variant $L$ ) only relies on the data given in Fellner et al. (2011), thus no analyses are considered for this option. For the other variants, at least information on the mass share of the different compounds $\left(x_{m, k}\right)$ is necessary, which can be derived from manual sorting. Besides $\mathrm{x}_{\mathrm{m}, \mathrm{k}^{\prime}}$ three further parameter are necessary to arrive at TOX $_{\text {Bio }}$ and TOX $_{\mathrm{Fos}}$ : The share of fossil or biogenic matter 
in in each sorted compound ( $x_{m F k}$ or $x_{m B k}$ ), and the chemical composition of fossil and biogenic matter of each sorted compound ( $\mathrm{TOX}_{\mathrm{k}}{ }^{\text {Fos }}$ and $\mathrm{TOX}_{\mathrm{k}}{ }^{\mathrm{Bio}}$ ). In the second variant, these parameters are all derived from literature (Variant LL); where $\mathrm{xmB}, \mathrm{k}$ is used as given in EN 15440:2011 and values for $\operatorname{TOX}_{k}{ }^{\text {Fos }}$ and $\operatorname{TOX}_{k}{ }^{B i o}$ are used as published by Kost (2001). In Variant AL and Variant LA either $x_{m B, k}$ or TOX $_{k}{ }_{k}$ os and TOX $_{k}{ }^{B i o}$ are used as revealed by own analyses (see section 2.4.1. for details on how $\mathrm{xmB}, \mathrm{k}$ is derived from analyses). Another option is to use all parameters, $x_{m B, k}$ and $\operatorname{TOX}_{k}{ }^{\text {Fos }}$ and $\operatorname{TOX}_{k}{ }^{\text {Bio }}$ as derived by own analyses (Variant AA).

However, assumption 2) implies that the composition of the sorted paper and plastics are representative for the composition of the paper and plastics contained in composite \& unrecognizable materials. This is expected to be false, especially for plastics, as different polymers have a different chemical composition. Plastics in composite materials are presumably dominated by plastics foils (e.g., made out of polyethylene), but the sorted plastics also contain significant shares of other polymers (e.g., PET, foamed plastics, polyamide).

Thus, the sixth Variant AAL to determine $\operatorname{TOX}_{\mathrm{Bio}^{\prime}}, \mathrm{TOX}_{\mathrm{Fos}}$ uses analyses results for $\mathrm{X}_{\mathrm{mB}, \mathrm{k}^{\prime}}$ and considers both sources (analyses and literature) for TOX ${ }_{k}^{\text {Fos }}$ and TOX $_{k}^{\text {Bio }}$. For example, analysis results are used for the sorted plastics but the composition of the plastics within the fine fraction and the composite \& unrecognizable materials fraction is assumed to correspond to a literature value for mixed plastics.

A sevenths variant (Variant Mean) is introduced which considers the mean value calculated of all values generated with "Variant AAL" of all RDF. This is to estimate the versatility and transferability of the generated data within this study.

Deviations for each variant from results of radiocarbon analyses or from manual sorting results are calculated as relative value (referred to the result of the standardized method). Negative deviations indicate that a lower value is found by aBM compared to the standardized method. Mean deviations between the aBM results and results of the radiocarbon/manual sorting are calculated by the mean aBM result of all RDFs compared to the mean radiocarbon/man- ual sorting result of all RDFs. Thus, no weighting according to the number of samples analyzed for the different RDFs is considered for the mean value.

Once one variant from Table 2 is chosen, the elemental composition of the water-and-ash-free biogenic and fossil organic matter $\left(\right.$ TOX $_{\mathrm{Bio},}$ TOX $_{\mathrm{Fos}}$ ) is calculated. The equations (2) and (3) are given exemplary for the determination of the water-and-ash-free carbon content in fossil matter $\left(\mathrm{TOC}_{\mathrm{Fos}}\right)$. First the relative share of each compound in the water-and-ash-free fossil matter is calculated by:

$x_{k}^{F o s}=\frac{x_{m, k} * x_{m F, k}}{\sum_{k=1}^{k=n} x_{m, k} * x_{m F, k}}$

$X_{k}^{\text {Fos: }}$ relative mass share of water-and-ash-free fossil compound $\mathrm{k}$ referred to total water-and-ash-free fossil matter in the RDF $\left[\mathrm{kg}_{\text {waf }} / \mathrm{kg}_{\text {waf }}\right]$ (e.g., fossil matter is composed out of plastics, foamed plastics, synthetic fibers, plastics in compounds)

- $x_{m, k}$ : relative mass share of water-and-ash-free compound $\mathrm{k}$ referred to total water-and-ash-free matter in the RDF $\left[\mathrm{kg}_{\text {waf }} / \mathrm{kg}_{\text {waf] }}\right.$ (e.g., share of plastics in the RDF)

- $X_{m F, k}$ : relative mass share of water-and-ash-free fossil matter in compound $\mathrm{k}$ referred to total water-and-ashfree matter in compound $\mathrm{k}\left[\mathrm{kg}_{\text {waf }} / \mathrm{kg}_{\text {waf }}\right]$ (e.g., in pure plastics there is $100 \mathrm{wt} \%$ of fossil matter if the sorting is precise; in composite materials there might be only $50 \mathrm{wt} \%$ fossil and the rest biogenic).

Then the carbon content in the water-and-ash-free fossil matter is calculated by:

TOC $_{\text {Fos }}=\frac{\sum_{k=1}^{k=n} \operatorname{TOC}_{k}^{\text {Fos }} * x_{k}^{\text {Fos }}}{\sum_{k=1}^{k=n} x_{k}^{\text {Fos }}}$

$\mathrm{TOC}_{\mathrm{Fos}}$ : carbon content in the water-and-ash-free fossil mat$\operatorname{ter}\left[\mathrm{g} / \mathrm{kg}_{\mathrm{waf}}\right]$

TOC ${ }_{k}^{\text {Fos: }}$ carbon content in the water-and-ash-free fossil matter of compound $\mathrm{k}\left[\mathrm{g} / \mathrm{kg}_{\text {wat }}\right.$ ]

Formula (3) is likewise used for the determination of the hydrogen, oxygen, nitrogen, and sulphur content in the water-and-ash-free fossil matter $\left(\mathrm{TOH}_{\mathrm{Fos}^{\prime}} \mathrm{TOO}_{\mathrm{Fos}^{\prime}} \mathrm{TON}_{\mathrm{Fos}^{\prime}} \mathrm{TOS}\right.$ Fos). Replacing the fossil share and fossil compounds by the biogenic share and biogenic compounds in formula (2)

TABLE 2: Variants within the study to derive information on the elemental composition of the water-and-ash-free biogenic and fossil organic matter present in the RDF (TOX Bio, TOX ${ }_{F o s^{\prime}}$ necessary input for aBM).

\begin{tabular}{|c|c|c|c|c|c|c|}
\hline & \multirow[t]{2}{*}{ Parameter } & \multirow[t]{2}{*}{$\begin{array}{l}\text { Mass share of com- } \\
\text { pounds in RDF } x_{m, k}\end{array}$} & \multicolumn{2}{|c|}{$\begin{array}{l}\text { Fossil and biogenic mass share in each sorted } \\
\text { compound } x_{m, k} \text { and } x_{m B, k} 1\end{array}$} & \multicolumn{2}{|c|}{$\begin{array}{l}\text { Chemical composition of fossil and biogenic mat- } \\
\text { ter in each sorted compound } \mathrm{TOX}_{\mathrm{k}}^{\mathrm{Fos}} \text { and } \mathrm{TOX}_{\mathrm{k}}^{\mathrm{Bio}}\end{array}$} \\
\hline & & & & Source/analysis method & & Source/analysis method \\
\hline 1 & Variant L & not necessary & Literature & - & Literature & $\begin{array}{l}\text { TOX }_{\text {Bio }} \text { and TOX } \\
\text { Fellner et al. }(2011)\end{array}$ \\
\hline 2 & Variant LL & Manual Sorting & Literature & EN 15440:2011 & Literature & Kost (2001) \\
\hline 3 & Variant AL & Manual Sorting & Analyses & $\mathrm{aBM}, \mathrm{SDM},{ }^{14} \mathrm{C}$ & Literature & Kost (2001) \\
\hline 4 & Variant LA & Manual Sorting & Literature & EN 15440:2011 & Analyses & CHNSO-analyses + ash content \\
\hline 5 & Variant AA & Manual Sorting & Analyses & $\mathrm{aBM}, \mathrm{SDM},{ }^{14} \mathrm{C}$ & Analyses & CHNSO-analyses + ash content \\
\hline 6 & Variant AAL & Manual Sorting & Analyses & $\mathrm{aBM}, \mathrm{SDM},{ }^{14} \mathrm{C}$ & $\begin{array}{l}\text { Analyses \& Lit- } \\
\text { erature values }\end{array}$ & $\begin{array}{c}\text { CHNSO-analyses }+ \text { ash content; } \\
\text { Kost (2001) }\end{array}$ \\
\hline 7 & Variant Mean & \multicolumn{5}{|c|}{ mean of TOX ${ }_{\text {Bio }}$ and TOX $\mathrm{Fos}_{\text {of }}$ all 6 RDFs determined by Variant AAL } \\
\hline
\end{tabular}

${ }^{1} \ldots$... Only $x_{m B, k}$ or $x_{m F, k}$ needs to be appraised as the other can be derived by $x_{m B, k}=1-x_{m F, k}$ 
gives the relative share of each biogenic compound within the water-and-ash-free biogenic matter. Subsequently formula (3) can be applied to determine TOX $_{\text {Bio }}$ in the same manner as TOX Fos . Results are then the carbon, hydrogen, oxygen, nitrogen, and sulphur content in the water-and-ashfree biogenic matter $\left(\mathrm{TOC}_{\mathrm{Bio}^{\prime}}, \mathrm{TOH}_{\mathrm{Bio}^{\prime}}, \mathrm{TOO}_{\mathrm{Bio}^{\prime}}, \mathrm{TON}_{\mathrm{Bio}^{\prime}}, \mathrm{TOS}_{\mathrm{Bio}}\right)$.

According to Table 2, different data sets for TOXBio, TOX $_{\text {Fos }}$ are generated; using different sources of data (literature values and/or analysis results). Evaluations by means of the aBM are conducted for each RDF sample by combining the analysis results on the elemental composition of the water-and-ash-free RDF (TOX $\left.{ }_{\mathrm{RDF}}\right)$ with each gen-

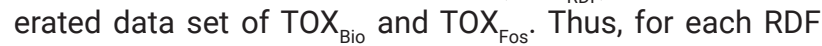
seven different results on the fossil share are obtained.

In order to appraise if the results are in the range of the true value, they are compared to radiocarbon analyses (regarded as method with highest accuracy). For RDF from producer B - RDF C\&I (2), (3), and (4) - no radiocarbon analyses are available. Thus, the results are compared to the sorting results only.

\subsection{Estimation of mass share of fossil and biogenic matter in each sorted compound $\mathbf{k}\left(\mathrm{x}_{\mathrm{mF}, \mathrm{k}}\right.$ and $\left.\mathrm{x}_{\mathrm{mB}, \mathrm{k}}\right)$}

For each sorted compound, a fossil and biogenic share needs to be allocated. To do this, the standard EN 15440:2011 provides some guiding values. However, these generic values are assumed to not be valid for every RDF. For example, the fossil content of composite materials and of textiles can vary, depending on the type of RDF. Textiles from industry usually contain a much higher share of synthetic fibers than natural fibers. Similarly, the plastic content in the fine fraction can easily vary between RDFs. In addition, the sorted compounds of alleged "pure" materials (like plastics or paper) may be contaminated by other compounds as the sorting cannot be conducted precisely and is also prone to subjective assessments.

Thus, within this study, the fossil and biogenic mass shares for each sorted compound are appraised. This is done by utilizing the analysis results of the elemental composition of each compound and conducting a preliminary evaluation using the aBM. TOX ${ }_{\mathrm{Bio}}$ and $\mathrm{TOX}_{\mathrm{Fos}}$ for these preliminary aBM evaluations stem from literature (Kost, 2011, Fellner et al., 2011) and theoretical considerations (e.g., composition of cotton and wool to derive TOX $_{\mathrm{Bio}}$ in the textiles).

In addition, the radiocarbon method (according to EN 15440:2011) is conducted for selected compounds to support and confirm the aBM results.

\section{RESULTS AND DISCUSSION}

\subsection{Composition of RDFs (sorting results) and as- signment of fossil share for each compound}

Table 3 presents the result of the sorting analyses of each investigated RDF. A share of plastics of at least $50 w t \%$ is found for all RDFs except Paper Reject (41wt\%). The fine fraction has a considerable share with $24 \mathrm{wt} \%$ to $65 \mathrm{wt} \%$; with the highest being found in Paper Reject. Table 4 shows that the fossil share (plastics content) in the fine fraction can vary significantly between the RDFs (between 40 and $78 w t \%)$. Thus, additional sorting of the this fraction are carried out for 3 RDFs to obtain more accurate results on the fractional composition of the RDFs.

The fine fraction, the composition of the composite \& unrecognizable materials is uncertain, which represents between 3 and 22wt\%. Fossil shares within this compound in the range of 32 and $66 \mathrm{wt} \%$ are found (Table 4).

\subsection{Elemental composition of sorted RDF com- pounds}

Table 5 presents the average elemental composition on water-and-ash-free basis of the different compounds found by analyses within this study. Comparing the results to values published in Kost (2001) shows that they are generally in a similar range. The small differences in TOC, $\mathrm{TOH}$, and TOO in plastics indicate the dependency on the

TABLE 3: Sorting results for the investigated RDFs - mass shares of compounds in each RDF.

\begin{tabular}{|c|c|c|c|c|c|c|c|c|c|}
\hline & \multicolumn{9}{|c|}{ Mass share $x_{m, k}[w t \%$ dry] } \\
\hline & \multicolumn{2}{|c|}{$\begin{array}{l}\text { Paper } \\
\text { Reject }\end{array}$} & \multicolumn{2}{|c|}{$\begin{array}{c}\text { RDF } \\
M S W+C \& I\end{array}$} & \multicolumn{2}{|c|}{$\begin{array}{l}\text { RDF C\&I } \\
\text { (1) }\end{array}$} & \multirow[t]{2}{*}{$\begin{array}{l}\text { RDF C\&I } \\
\text { (2) }\end{array}$} & \multirow[t]{2}{*}{$\begin{array}{l}\text { RDF C\&I } \\
\text { (3) }\end{array}$} & \multirow[t]{2}{*}{$\begin{array}{c}\text { RDF C\&I } \\
\text { (4) }\end{array}$} \\
\hline & & $\begin{array}{l}\text { incl. sorting of } \\
\text { fine fraction }\end{array}$ & & $\begin{array}{l}\text { incl. sorting of } \\
\text { fine fraction }\end{array}$ & & $\begin{array}{l}\text { incl. sorting of } \\
\text { fine fraction }\end{array}$ & & & \\
\hline Paper & $5.9 \%$ & $37.4 \%$ & $4.1 \%$ & $5.1 \%$ & $2.8 \%$ & $6.9 \%$ & $5.0 \%$ & $5.1 \%$ & $8.5 \%$ \\
\hline Wood & $1.6 \%$ & $2.5 \%$ & $2.2 \%$ & $1.9 \%$ & $0.1 \%$ & $0.2 \%$ & $0.4 \%$ & $0.3 \% \%$ & $0.2 \%$ \\
\hline Plastics & $20.4 \%$ & $41.0 \%$ & $47.1 \%$ & $56.5 \%$ & $32.5 \%$ & $49.6 \%$ & $54.0 \%$ & $53.3 \%$ & $50.1 \%$ \\
\hline $\begin{array}{l}\text { Composite \& } \\
\text { unrecognizable } \\
\text { materials }\end{array}$ & $3.0 \%$ & $15.0 \%$ & $8.4 \%$ & $11.7 \%$ & $21.8 \%$ & $40.7 \%$ & $9.4 \%$ & $4.4 \%$ & $4.7 \%$ \\
\hline Textiles & $1.1 \%$ & $1.1 \%$ & $12.1 \%$ & $22.6 \%$ & $0.7 \%$ & $1.4 \%$ & $1.3 \%$ & $0.9 \%$ & $7.3 \%$ \\
\hline Rubber & $0.7 \%$ & $0.7 \%$ & $0.8 \%$ & $0.9 \%$ & $0.1 \%$ & $0.4 \%$ & $0.4 \%$ & $0.3 \%$ & $1.2 \%$ \\
\hline $\begin{array}{c}\text { Fine fraction } \\
\text { (around }<1-2 \\
\mathrm{~cm} \text { ) }\end{array}$ & $65.1 \%$ & - & $24.1 \%$ & - & $41.3 \%$ & - & $28.4 \%$ & $32.9 \%$ & $27.1 \%$ \\
\hline $\begin{array}{c}\text { Metals \& inert } \\
\text { materials }^{1}\end{array}$ & $2.2 \%$ & $2.3 \%$ & $1.2 \%$ & $1.3 \%$ & $0.7 \%$ & $0.8 \%$ & $1.1 \%$ & $2.8 \%$ & $0.9 \%$ \\
\hline
\end{tabular}

${ }^{1}$ Metals \& inert materials are not further considered in the study (these compounds are neither of fossil nor of biogenic origin). 
TABLE 4: Allocated fossil share in each sorted compound in the RDF.

\begin{tabular}{|c|c|c|c|c|c|c|c|}
\hline & \multicolumn{7}{|c|}{ Allocated fossil share $x_{m F, k}[w t \%, d r y]$} \\
\hline & $\begin{array}{l}\text { Paper } \\
\text { Reject }\end{array}$ & $\begin{array}{c}\text { RDF } \\
\text { MSW+C\&I }\end{array}$ & $\begin{array}{l}\text { RDF C\&I } \\
\text { (1) }\end{array}$ & $\begin{array}{l}\text { RDF C\&I } \\
\text { (2) }\end{array}$ & $\begin{array}{l}\text { RDF C\&I } \\
\text { (3) }\end{array}$ & $\begin{array}{l}\text { RDF C\&I } \\
\text { (4) }\end{array}$ & EN 15440:2011 ${ }^{1}$ \\
\hline Paper & $7 \%$ & $8 \%$ & $7 \%$ & $7 \%$ & $6 \%$ & $4 \%$ & $0 \%$ \\
\hline Wood & $1 \%$ & $1 \%$ & $1 \%$ & $5 \%$ & $2 \%$ & $4 \%$ & $0 \%$ \\
\hline Plastics & $95 \%$ & $92 \%$ & $96 \%$ & $96 \%$ & $98 \%$ & $98 \%$ & $100 \%$ \\
\hline $\begin{array}{c}\text { Composite \& } \\
\text { unrecognizable } \\
\text { materials }\end{array}$ & $66 \%$ & $54 \%$ & $42 \%$ & $40 \%$ & $32 \%$ & $56 \%$ & $\mathrm{NA}^{2}$ \\
\hline Textiles & $35 \%$ & $55 \%$ & $55 \%$ & $40 \%$ & $45 \%$ & $98 \%$ & $50 \%$ \\
\hline Rubber & NA & NA & NA & $84 \%$ & $84 \%$ & $75 \%$ & $80 \%$ \\
\hline $\begin{array}{c}\text { Fine fraction } \\
(\text { around }<1-2 \mathrm{~cm})\end{array}$ & $40 \%$ & $62 \%$ & $55 \%$ & $72 \%$ & $78 \%$ & $77 \%$ & $50 \%$ \\
\hline
\end{tabular}

1 Used for Variant LL and Variant LA

${ }^{2} 50 \%$ were used as there is no guiding value in the EN 15440:2011

TABLE 5: Elemental composition of different waste compounds analyzed in this study, compared to data published in Kost (2001).

\begin{tabular}{|c|c|c|c|c|c|c|}
\hline & \multicolumn{6}{|c|}{ Elemental composition (water-and-ash-free) } \\
\hline & $\mathbf{N}$ & $\begin{array}{c}\text { TOC } \\
{\left[\mathrm{g} / \mathrm{kg}_{\mathrm{waf}}\right]}\end{array}$ & $\begin{array}{c}\mathrm{TOH} \\
{\left[\mathbf{g} / \mathbf{k g}_{\mathrm{waf}}\right]}\end{array}$ & $\begin{array}{c}\text { TOO } \\
{\left[\mathrm{g} / \mathrm{kg}_{\mathrm{waf}}\right]}\end{array}$ & $\begin{array}{c}\text { TON } \\
{\left[\mathbf{g} / \mathbf{k g}_{\text {waf }]}\right.}\end{array}$ & $\begin{array}{c}\text { TOS } \\
{\left[\mathbf{g} / \mathbf{k g}_{\mathrm{waf}}\right]}\end{array}$ \\
\hline \multicolumn{7}{|l|}{ Paper } \\
\hline this study & 21 & $476 \pm 3$ & $65 \pm 1$ & $497 \pm 4$ & $3.6 \pm 0.5$ & $5.1 \pm 1.0$ \\
\hline Kost $(2001)^{1}$ & $43-62$ & $467 \pm 6$ & $65 \pm 1$ & $443 \pm 9$ & $2 \pm 1$ & $1 \pm 0$ \\
\hline \multicolumn{7}{|l|}{ Wood } \\
\hline this study & 10 & $498 \pm 2$ & $62 \pm 1$ & $453 \pm 2$ & $6.3 \pm 0.5$ & $7.6 \pm 1.2$ \\
\hline Kost $(2001)^{1}$ & $21-30$ & $494 \pm 2$ & $60 \pm 1$ & $443 \pm 4$ & $1 \pm 0$ & $0 \pm 0$ \\
\hline \multicolumn{7}{|c|}{ Plastics (mixed) } \\
\hline this study & 24 & $771 \pm 6$ & $109 \pm 1$ & $103 \pm 2$ & $7.0 \pm 0.5$ & $8.4 \pm 0.5$ \\
\hline Kost (2001)1 & $11-15$ & $790 \pm 29$ & $130 \pm 9$ & $30 \pm 32$ & $2 \pm 2$ & $1 \pm 2$ \\
\hline \multicolumn{7}{|c|}{ Composite \& unrecognizable materials } \\
\hline this study & 16 & $620 \pm 13$ & $88 \pm 2$ & $286 \pm 5$ & $2.9 \pm 0.5$ & $9.5 \pm 1.0$ \\
\hline Kost $(2001)^{2}$ & $1-8$ & $560 \pm 16$ & $80 \pm 3$ & $320 \pm 4$ & $11 \pm$ & $4 \pm$ \\
\hline \multicolumn{7}{|l|}{ Textiles } \\
\hline this study & 15 & $564 \pm 4$ & $65 \pm 1$ & $355 \pm 5$ & $13.5 \pm 0.6$ & $11.2 \pm 1.5$ \\
\hline Kost (2001) & $4-11$ & $510 \pm 16$ & $70 \pm 3$ & $360 \pm 7$ & $27 \pm 11$ & $4 \pm 2$ \\
\hline \multicolumn{7}{|l|}{ Rubber } \\
\hline this study & $6-9$ & $733 \pm 4$ & $90 \pm 1$ & $78 \pm 4$ & $14.6 \pm 1.2$ & $24.9 \pm 2.7$ \\
\hline Kost (2001) & $4-5$ & $860 \pm 13$ & $80 \pm 9$ & $60 \pm 21$ & $4 \pm 1$ & $17 \pm 4$ \\
\hline \multicolumn{7}{|c|}{$\begin{array}{l}\text { N Number of analyzed samples / number of literature values collected (by Kost, 2001). } \\
{ }^{1} \text { Used for Variant LL and Variant AL. } \\
{ }^{2} \text { Composite packaging. }\end{array}$} \\
\hline
\end{tabular}

plastics composition (shares of polyethylene, polyethylene terephthalate, polyurethane, etc.).

Further, differences of the analyzed values compared to the literature values are noticeable for rubber and textiles. For textiles this could be explained by high shares of synthetic fibers (with higher TOC, TOH and lower TOO content) which were observed for some RDF samples within this study.

Some differences in the oxygen content (TOO) are noticeable for almost all compounds. One factor explaining this phenomenon is assumed to be the chosen determination method. In literature, the O-content is often derived by subtracting all other elements from $1000 \mathrm{~g} / \mathrm{kg}$. Within this study, 0-analyses are conducted by means of pyrolysis. It is assumed that the subtracting method holds higher uncertainties than actual analyses and can easily lead to different or wrong estimations of the 0-content because the analytical uncertainty of the other elements is not considered.

\subsection{Share of fossil carbon present in RDFs - aBM re- sults based on literature values and based on anal- ysis values}

Figure 2 shows the outcomes of the aBM, namely the 
share of fossil carbon for each investigated RDF. In particular, the different results depending on the variant utilized to derive the input data (elemental composition of biogenic and fossil organic matter TOX $\mathrm{Bio}_{\text {and }}$ an $\mathrm{X}_{\mathrm{Fos}}$ ) are presented.

The results for the fossil carbon share (which represents also the share of fossil $\mathrm{CO}_{2}$-emissions when the RDF are thermally utilized) vary only in a small range for Paper Reject (52-59\% fossil carbon); no significant difference can be detected when comparing results generated with literature values, analysis values or a combination of both (Variant $L L, A L, L A, A A, A A L)$. This is different for the other RDFs: The determined fossil carbon shares range from 72 to $92 \%$. A significant difference can be observed for values where the elemental composition of biogenic and fossil organic matter in the compounds ( TOX $_{k}{ }^{\text {Fos }}$ and $\operatorname{TOX}_{k}{ }^{B i o}$ ) is derived from literature values only (blue bars in Figure 2) and where these values are determined by own analyses (green bars in Figure 2). The differences between the variants where the fossil mass share per compound $\left(x_{m F, k}\right)$ was varied (according to EN 15440:2011 or own appraisal) appear to be minor (differences between Variant $L L$ and $A L$ and difference between Variant $L A$ and $A A$ ). This suggests that the choice of the chemical composition of the different compounds ( $\mathrm{TOX}_{\mathrm{k}}{ }^{\mathrm{Fos}}$ and $\mathrm{TOX}_{\mathrm{k}}^{\mathrm{Bio}}$ ) has a much higher influence on the aBM result than the estimated fossil and biogenic mass share in each sorted compound $\left(x_{m F, k}\right.$ and $\left.x_{m B, k}\right)$. The small differences between Variant $L L$ and $A L$ and between Variant LA and AA are mainly caused by the allegedly false estimation of the fossil mass share in the fine fraction and textiles (as given in EN 15440:2011) and of composite \& unrecognizable materials (50\% were estimated) (see Table 4). If the shares of these "non-pure" compounds are high, then the result according to the standard are expected to be more prone to errors.
From Figure 2 it can be seen, that the estimated fossil shares are lowest when literature values are used for $\operatorname{TOX}_{k}{ }_{k}^{\text {Fos }}$ and $\operatorname{TOX}_{\mathrm{k}}$ Bio (blue bars, Variant $\mathrm{LL}$ and $\mathrm{AL}$ ). This implies that the generated TOX $\mathrm{Bio}_{\mathrm{Bi}}$ is closer to the measured values in the

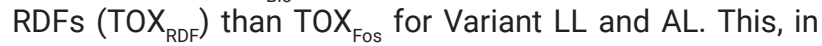
turn indicates that the actual carbon and hydrogen content in the TOX $_{\text {Fos }}$ is lower than expected from literature values; and the oxygen content is higher. As the TOX $_{\text {Fos }}$ depends on the different shares of polymers and their respective chemical composition, it can be expected that the polyethylene and polypropylene shares in the investigated RDF is lower than typically found in MSW. They may contain slightly higher shares of plastics with lower carbon and hydrogen and higher oxygen contents (e.g., polyamide, polyethylene terephthalate, or polyurethane). For example, in RDF $M S W+C \&$ significant shares of foamed polymers could be observed, which are expected to account for around 16 to $26 w t \%$. In RDF C\&I (2), (3), and (4) shares of foamed plastics between 2 to $3 w t \%$ could be assessed by sorting, which corresponds to 4 to $5 \mathrm{wt} \%$ in the plastic compound sorted out.

The fact that there are much smaller differences for Paper Reject (than for the other RDFs) when comparing results obtained using different $\operatorname{TOX}_{\mathrm{k}}{ }^{\mathrm{Fos}}$ and $\mathrm{TOX}_{\mathrm{k}}^{\mathrm{Bio}}$ (green bars versus blue bars in Figure 2), suggests that the polymer composition in the Paper Reject is similar to the one typically found in MSW.

For all RDFs prepared from mainly C\&l (4 of the 6 RDFs investigated), the results generated using values for TOX and TOX $_{\text {Fos }}$ from Fellner et al. (2011) (Variant L, grey bar in Figure 2) are close to the results generated when using $\operatorname{TOX}_{k}{ }^{\text {Fos }}$ and $\operatorname{TOX}_{k}$ Bio from own analyses or combining own analyses with literature values (Variant $L A, A A$, and $A A L$ ).

The Variant AAL delivers aBM results on the fossil car-

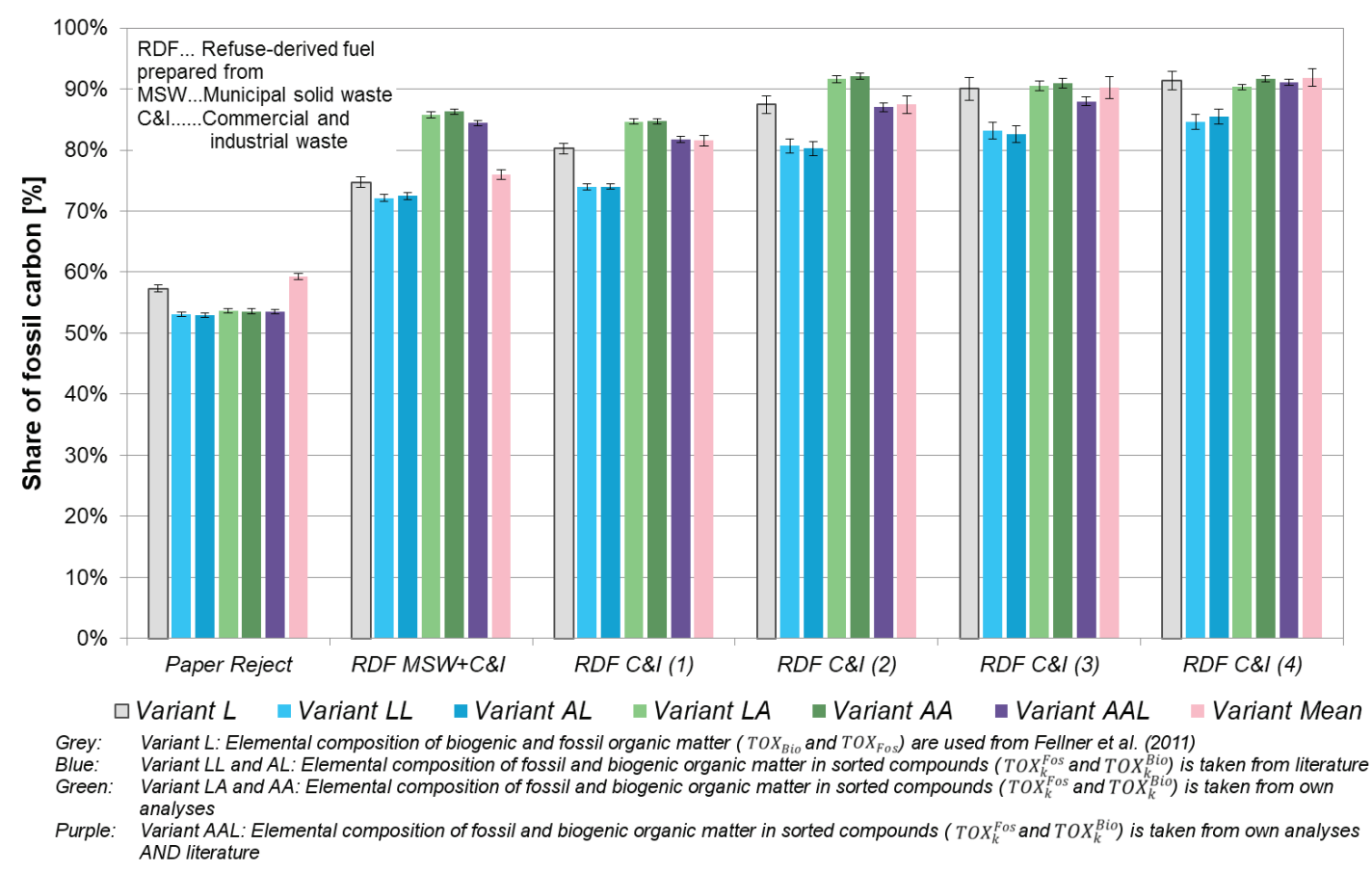

FIGURE 2: Share of fossil carbon for the different RDFs, determined by utilizing the aBM with different input values of TOX Fos $_{\text {and TOX }}$ (estimated by using 7 different variants as listed in Table 2). 
bon share which are slightly below the ones when using $\operatorname{TOX}_{k}$ Fos and TOX ${ }_{k}^{\text {Bio }}$ from own analyses (Variant LA and AA, green bars), but are in most cases considerably above the ones when using literature values (Variant $L L$ and $A L$ ). The Variant Mean, which uses the mean values of all investigat-

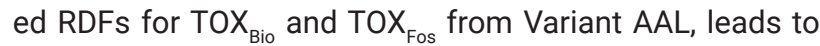
results in a similar range as Variant AAL except for Paper Reject and RDF MSW+C\&I.

In general, by trend a slightly higher fossil share can be detected for RDFs prepared from C\&I (RDF C\&I), compared to the RDF containing also compounds of MSW (RDF MSW+C\&l).

\subsection{Comparison of aBM results to alternative methods}

In order to decide on the most probable result determined by aBM (to identify which variant delivers the lowest deviation from a comparable value), the outcomes are compared to values generated with alternative analysis methods.

Figure 3 shows the deviation of the aBM results from values generated by using the Radiocarbon method $\left({ }^{14} \mathrm{C}\right.$-method) for 3 of the investigated RDFs. Figure 4 presents the deviation of the aBM results from the manual sorting results for the other 3 RDFs (no Radiocarbon analyses are available for these RDFs). However, it must be kept in mind that the manual sorting results are connected with a significantly higher uncertainty than the results of Radiocarbon analyses. Even though the sorting is conducted very painstakingly, some errors (such as subjectiveness when sorting, wrong estimation of the composition of fine fraction or composite \& unrecognizable materials) are hardly quantifiable.

For Paper Reject and RDF MSW+C\&I using generic values or mean values for TOX Fos $_{\text {and }}$ TOX ${ }_{\text {Bio }}$ (Variant $L$ and Variant $M$ ) seems not to be suitable ( +8 to $+12 \%$ deviation for Paper Reject and -8 to $-10 \%$ deviation for RDF MSW+C\&l compared to Radiocarbon analyses).
For the other RDFs, which are the ones mainly produced out of C\&l, a relatively good agreement of the aBM results to the results of alternative methods is observed when using Variant $L$ or Variant M. Low deviations between $-2.9 \%$ and $+3.2 \%$ from results of alternative methods are found. This indicates that the usage of generic values is suitable and RDF produced out of C\&I have typical compositions regarding the shares of the different synthetic polymers (within the fossil fraction) and regarding the composition within the biogenic materials (shares of paper, wood, natural fibers, etc.).

The results for all other variants than Variant $L$ and Variants $M$, are in a close range when regarding Paper Reject. As Variant $L L, A L, L A, A A$, and $A A L$ also show a low deviation from the alleged true value ( 0.5 to $1.6 \%)$, it can be assumed that the most decisive factor when generating $\operatorname{TOX}_{\mathrm{Fos}}$ and TOX $_{\text {Bio }}$ is the usage of the actual shares of compounds present in Paper Reject. This means that an initial sorting campaign before applying the aBM to Paper Reject might results in a considerably higher reliability of the results.

A somehow different observation is made for the other RDFs: Significant underestimations of the fossil share can be observed when Variant LL and LA are used, where the information of the chemical composition of biogenic and fossil organic matter in the compounds stem from literature (mean deviation -9 to $-13 \%$ ). But the usage of the analyzed chemical composition of the compounds (Variant LA) or only analysis results (Variant AA) seems to rather overestimate the fossil carbon share for all RDFs. For example, for RDF C\&I (2) the relative deviation when using Variant $A A$ is considerably higher than when using Variant $L$ where the input values for $\operatorname{TOX}_{\text {Fos }}$ and TOX $_{\text {Bio }}$ are used without any analysis (values from Fellner et al., 2011). A possible explanation for this phenomenon is that the fossil and biogenic matter in the fine fraction, which represents

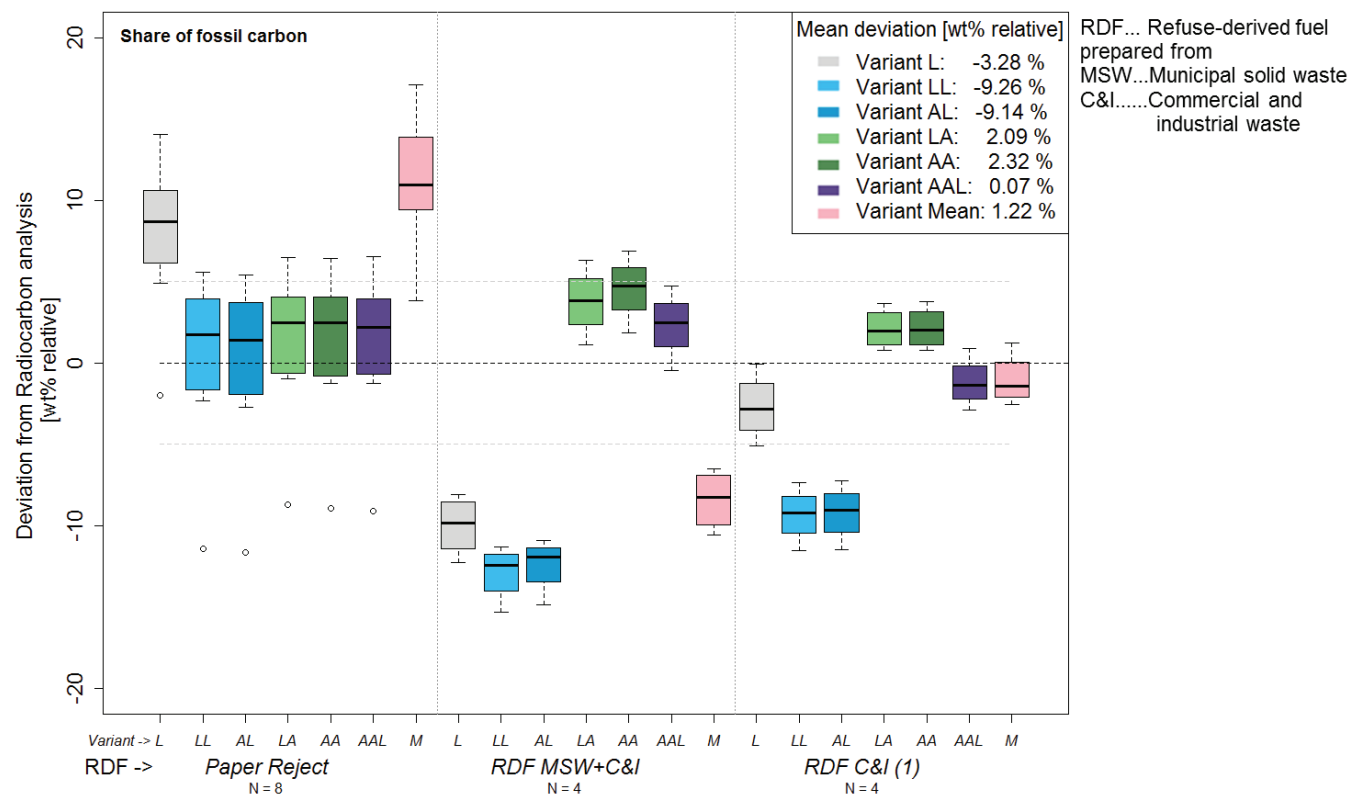

FIGURE 3: Deviations of the fossil carbon share as determined by the aBM from results determined by the Radiocarbon method; aBM results are generated by utilizing different input values of $\mathrm{TOX}_{\mathrm{Fos}}$ and $\mathrm{TOX}_{\mathrm{Bio}}$ ( 7 different variants as listed in Table 2 are used); negative deviations mean a lower value is found by aBM compared to the Radiocarbon method. One outlier is identified for Paper Reject. 


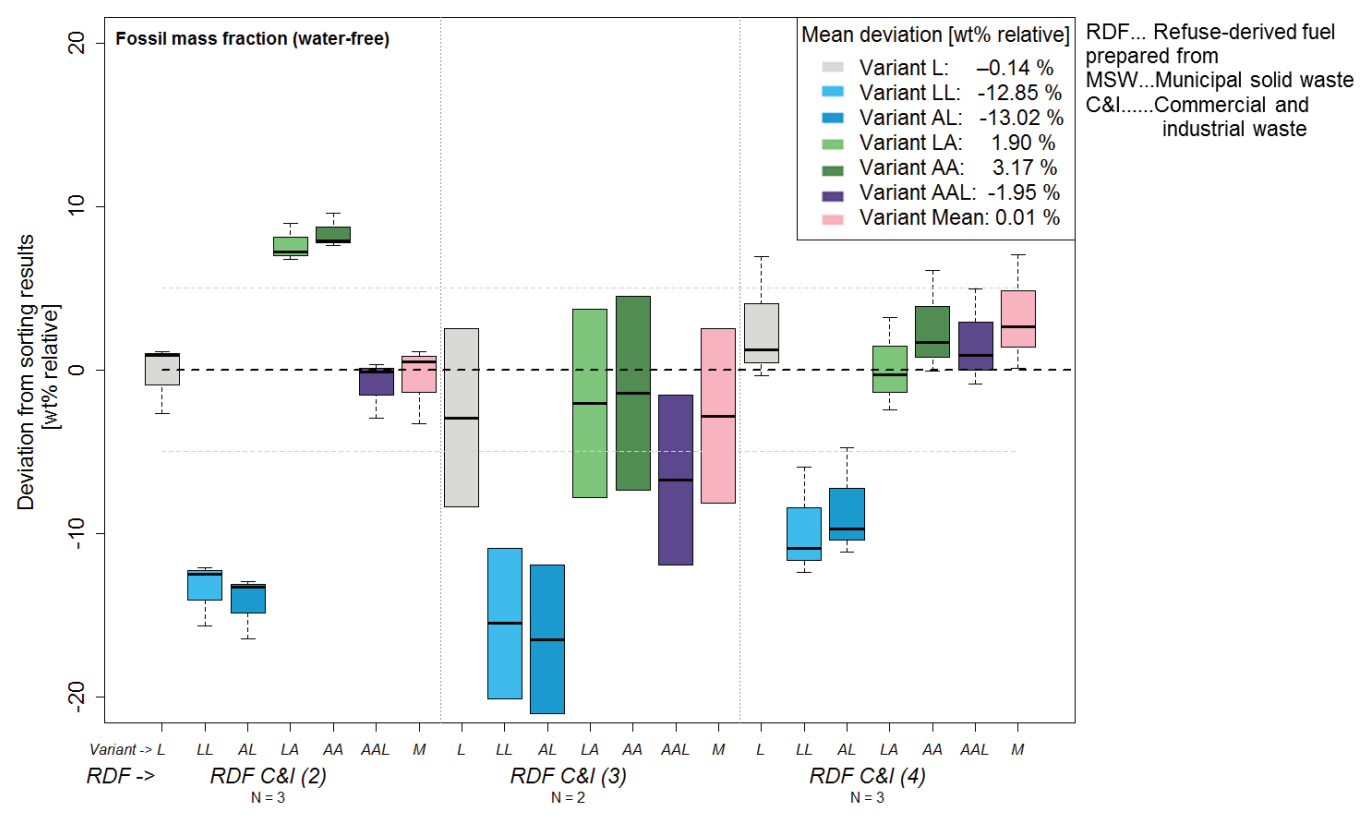

FIGURE 4: Deviations of the fossil mass fraction (water-free) as determined by the aBM from results determined by manual sorting; aBM results are generated by utilizing different input values of $\operatorname{TOX}_{\mathrm{Fos}}$ and $\operatorname{TOX}_{\mathrm{Bio}}$ ( 7 different variants as listed in Table 2 are used); negative deviations mean a lower value is found by aBM compared to manual sorting.

almost $1 / 3$ of the mass of the RDF, has a significantly different chemical composition than the fossil and biogenic matter in the rest of the RDF. This would make the assignment of analysis results of, for example, plastics, and paper to the fine fraction incorrect (which is done for Variant LA and Variant AA). For Variant AAL, it is assumed that the fine fraction has a chemical composition similar to the one reported in the literature. This assumption appears to lead to more accurate results compared to the other variants. The boxplots per RDF in Figure 3 and Figure 4 show that the results of Variant AAL deviate from the result of the alternative method less than $2.5 \%$ (except for RDF C\&I (3) where only 2 values are available and thus, one value can easily distort the average deviation).

A mean deviation for the Variant AAL of $0.07 \%$ is found when comparing the aBM results to the Radiocarbon results (see Figure $5 \mathrm{a}$ ). When considering the sorting results as alleged target value (although the uncertainty of these values are relatively high) a mean deviation of $-1.95 \%$ is found (Figure $5 b$ ). Although this mean deviation might be higher than found for other variants, a lower variation of results is visible from Figure $5 b$ for this variant than for the
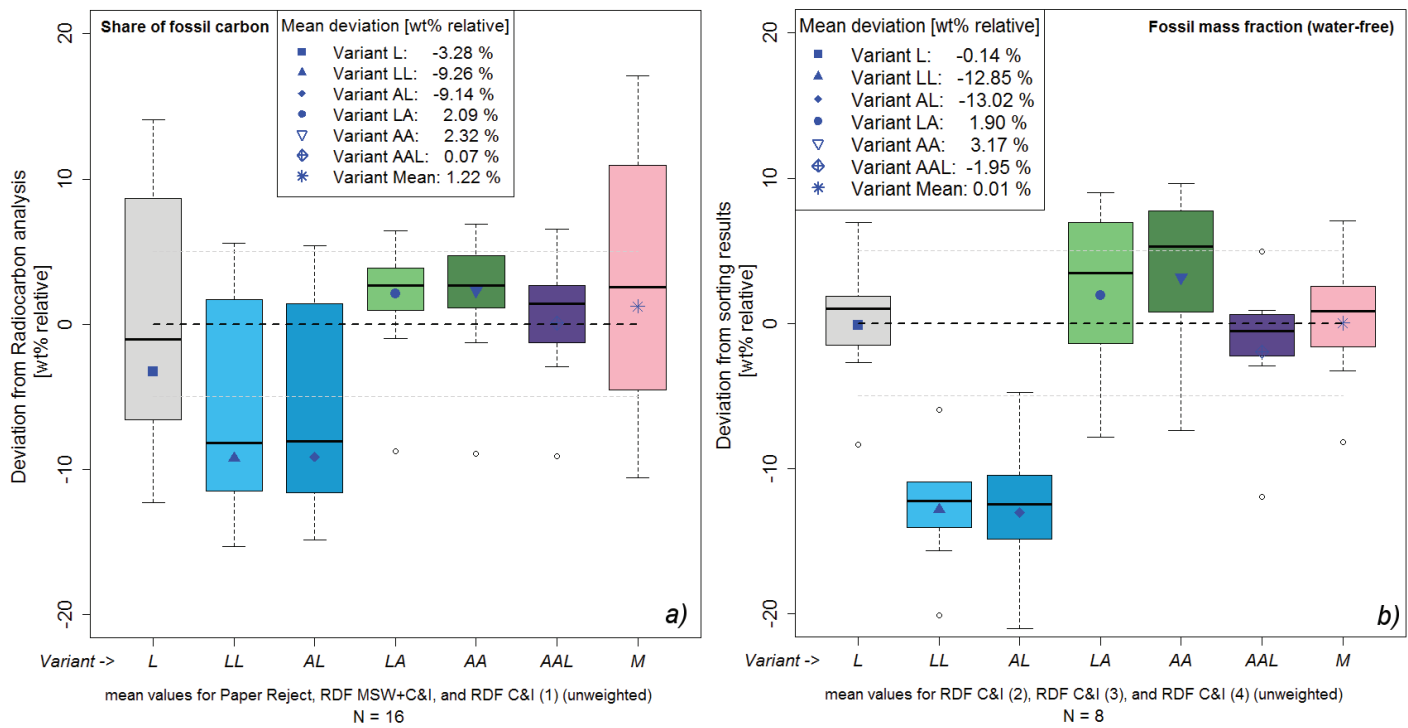

FIGURE 5: a) Deviations of the fossil carbon share as determined by the aBM from results determined by the Radiocarbon method.

b) Deviations of the fossil mass fraction (water-free) as determined by the aBM from results determined by manual sorting. Negative deviations mean a lower value is found by aBM compared to the alternative method; Outliers in a) stem from one Paper Reject sample and in b) from one sample of RDF C\&I (3) and from one sample of RDF C\&I (4). 
other options. Treating one of the values for RDF C\&I (3) as outlier (only 2 values available, so no clear judgement can be made), results in a mean deviation of only $-0.2 \%$ for Variant AAL when compared to manual sorting. The results which are obtained by applying Variant AAL are considered to result in a good agreement with the alternative methods.

\subsection{Elemental composition of biogenic and fossil or- ganic matter present in RDFs}

Based on the results found in the previous sections, the Variant AAL is identified as the most suitable option to generate the input parameter $\left(\mathrm{TOX}_{\mathrm{Fos}}\right.$ and $\left.\mathrm{TOX}_{\mathrm{Bio}}\right)$ required for the aBM. In Figure 6 and Figure 7 the results for these parameters are presented and compared to values given in Fellner et al. (2011). Additionally the mean for each element is indicated together with the $95-\%$ confidence inter- val determined for all the RDFs investigated in this study.

It can be seen that the values for all RDFs are in a relatively close range and also similarly to values found in Fellner et al. (2011) for most elements. The most varying value seems to be the total organic oxygen content (TOO). The TOO values generated within this study vary $\pm 21 \mathrm{~g} / \mathrm{kg}$ on average in the fossil organic matter and $\pm 36 \mathrm{~g} / \mathrm{kg}$ on average in the biogenic organic matter. This variation is partly due to the fact that conducting oxygen analyses is more difficult than for the other elements. Higher uncertainties need to be considered. Further, values reported in literature often only estimate the 0 -content based on the subtraction of the all other elements from $1000 \mathrm{~g} / \mathrm{kg}$.

The higher TOO content found in the fossil organic matter of RDF MSW+C\&I indicates higher shares of polyamide, polyethylene terephthalate, or polyurethane. Whereas, the

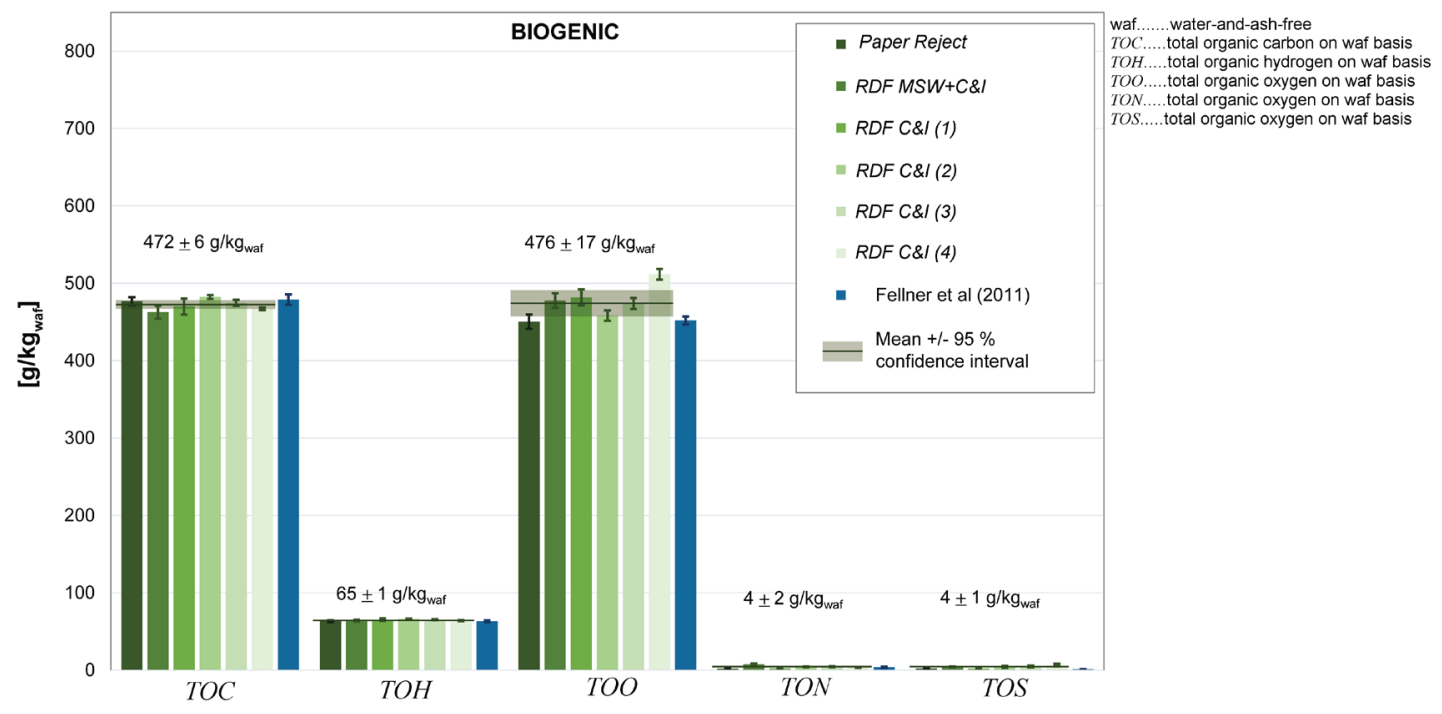

FIGURE 6: Elemental composition of biogenic organic matter $\left(\mathrm{TOX}_{\mathrm{Bio}}\right)$ present in the RDFs (determined according to Variant AAL described in Table 2).

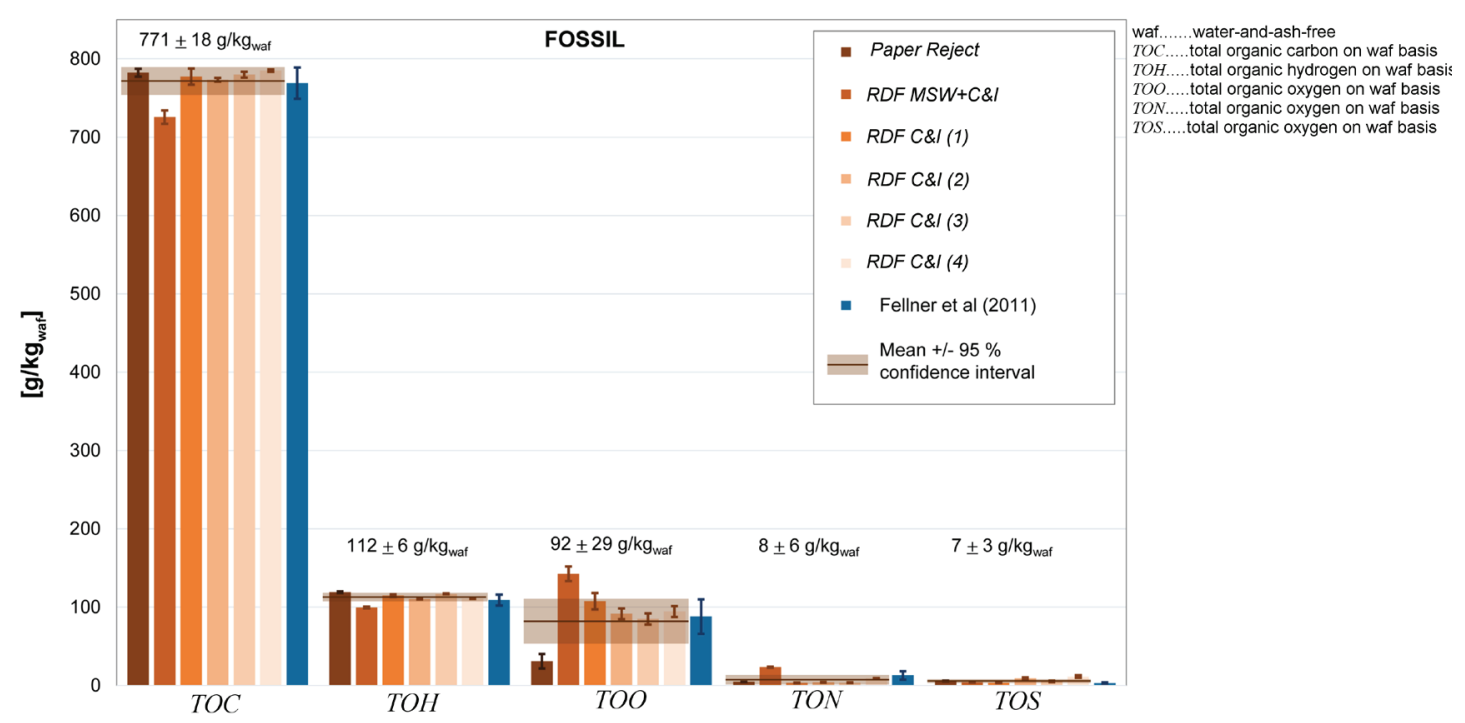

FIGURE 7: Elemental composition of fossil organic matter ( TOX $_{F o s}$ ) present in the RDFs (determined according to Variant AAL described in Table 2). 
Paper Reject can be estimated to contain high shares of polyethylene and polypropylene, which are characterized by a low or even zero oxygen content.

It can be seen that the values found for the RDFs C\&l (1), (2), (3), (4) are in an even closer range than when all RDFs are regarded. Except for the TOC ${ }_{B i o}$ of RDF C\&I (2) and $\mathrm{TOO}_{\text {Bio }}$ of RDF C\&I (4) all values are within the 95-\% confidence interval given in Figure 6 and 7 .

\section{CONCLUSION}

The presented study shows that the shares of different compounds in RDFs (such as paper, plastics, textiles, etc.) can vary significantly, even when the RDFs are produced from allegedly similar waste material (such as C\&I). Also the fossil shares in mixed compounds (mix of biogenic and fossil materials, such as in composite materials, textiles, fine fraction) can be considerably different between RDFs and compared to the suggested values in EN 15440:2011. However, for most RDFs these inaccuracies hardly influence the results of the adapted Balance method (aBM) and thus the determination of the fossil carbon share when applying this method.

The usage of generic values from literature or of an overall mean from this study leads to deviations from the allegedly true value of $<3.5 \%$ when 4 different RDFs C\&I are regarded. This finding suggests that there is a typical elemental composition of biogenic and fossil organic matter present in RDFs which are produced out of C\&l (RDF C\&I). It is expected that the values derived for this type of RDF on TOX Fos $_{\text {and TOX }}$ Bio can also be used for other RDFs of the same type. Yet, as the investigated samples stem from Austrian RDF producers, the question on the country-specific dependency remains unclear.

For RDFs where the input is more prone to strong variations (which might be expected from MSW), the initial generation of RDF-specific values on the chemical composition of biogenic and fossil organic matter $\left(\mathrm{TOX}_{\mathrm{Fos}}\right.$ and $\mathrm{TOX}_{\mathrm{Bio}}$ ) is recommended to increase the reliability of the aBM results. This also applies when special types of RDF are to be analyzed for their climate relevance (like Paper Reject).

The usage of previously collected literature values for MSW compounds seem not to be suitable for most of the investigated RDFs. Thus, if sorting analyses are conducted it makes sense to generate some data on the elemental composition of the different compounds. These could not only be used to increase the accuracy of the results but could also be collected in a database for different RDF types to be accessed for future investigations.

However, in the case of Paper Reject, the usage of the actual shares of the different compounds in the RDF appears to be the most decisive factor. Thus, if this type of RDF is to be analyzed for its fossil carbon content by means of the aBM, manual sorting campaigns for determining the share of the different compounds are sufficient; the chemical composition of the sorted compounds can be taken from previously analyzed Paper Reject (e.g., from this study).

Some workload can be saved for the determination of the fossil and biogenic share in each compound of the RDF $\left(x_{m F k}\right.$ and $\left.x_{m B k}\right)$; this parameter seems to have a minor influence on the aBM result. Only when the share of textiles, composite \& unrecognizable materials or of the fine fraction is significant (and compounds are expected to contain a significantly higher amount of plastics than $50 \mathrm{wt} \%$ ), then $\mathrm{x}_{\mathrm{mF}, \mathrm{k}}$ and $\mathrm{x}_{\mathrm{mB}, \mathrm{k}}$ should also be investigated specifically for these "mixed" compounds (mix of fossil and biogenic constituents).

In general, the results obtained by combining own analysis data with information from the literature are in a good agreement with the outcomes of alternative methods (relative mean deviation $<2 \%$ ). Moreover, the results are also less scattered when choosing this option. Thus, it is assumed Variant AAL represents the best option to generate the necessary input data for the aBM ( TOX $_{\text {Fos }}$ and TOX $\left.\mathrm{Bio}_{\mathrm{Bio}}\right)$.

It can be concluded that if more data on $\operatorname{TOX}_{\mathrm{Fos}}$ and TOX $_{\text {Bio }}$ are collected in a database, generic values can be derived for different RDF types and the initial workload and costs for conducting sorting analyses of RDF before applying the aBM can be saved.

The aBM delivers information on the fossil and biogenic mass share, the fossil and biogenic carbon $\left(\mathrm{CO}_{2}\right)$ share and also the share of biogenic and fossil energy recovered from the RDF can be estimated. The heating value for the biogenic and fossil matter in the RDF can, for example, be estimated using an empirical equation based on the elemental composition (e.g., Garcés et al., 2016; Kost, 2001; Meraz et al., 2003). Thus, the aBM can be regarded as cost-efficient method which has been demonstrated to deliver reliable results.

\section{ACKNOWLEDGEMENTS}

The authors would like to acknowledge the funding of the present study, which was provided by the Austrian Science Fund (FWF), project number TRP 285-N28. Further, the work was partly supported by a large-scale research initiative on anthropogenic resources (Christian Doppler Laboratory for Anthropogenic Resources). The financial support of this research initiative by the Austrian Federal Ministry of Science, Research and Economy and the National Foundation for Research, Technology and Development is gratefully acknowledged. We thank the RDF-plant operators and paper \& board plant operators for their support and assistance for drawing samples. Thanks to the laboratory team of TU Wien for their contribution as well as Inge Hengl for graphical support. In addition, we are grateful for the assistance of Edith Vogel during ${ }^{14} \mathrm{C}$ analysis.

\section{REFERENCES}

Aranda Usón, A., López-Sabirón, A.M., Ferreira, G., Llera Sastresa, E., 2013. Uses of alternative fuels and raw materials in the cement industry as sustainable waste management options. Renewable and Sustainable Energy Reviews 23, 242-260.

EN 15403:2011. Solid recovered fuels - Determination of ash content European Committee for Standardization, 10 pages.

EN 15407:2011. Solid recovered fuels - Methods for the determination of carbon $(\mathrm{C})$, hydrogen $(\mathrm{H})$ and nitrogen $(\mathrm{N})$ content. DIN Deutsches Institut für Normung e. V., Berlin, 16 pages.

EN 15440:2011. Solid recovered fuels - Methods for the determination of biomass content. DIN Deutsches Institut für Normung e. V., 60 pages. 
EN 15413:2011. Solid recovered fuels - Methods for the preparation of the test sample from the laboratory sample. DIN Deutsches Institut für Normung e. V., 39 pages.

Fellner, J., Aschenbrenner, P., Cencic, O., Rechberger, H., 2011. Determination of the biogenic and fossil organic matter content of refuse-derived fuels based on elementary analyses. Fuel 90, 31643171.

Fellner, J., Rechberger, H., 2009. Abundance of ${ }^{14} \mathrm{C}$ in biomass fractions of wastes and solid recovered fuels. Waste Manage 29, 14951503.

Garcés, D., Díaz, E., Sastre, H., Ordóñez, S., González-LaFuente, J.M., 2016. Evaluation of the potential of different high calorific waste fractions for the preparation of solid recovered fuels. Waste Manage 47 , Part $B, 164-173$.

ISO 18466:2016 - Stationary source emissions - Determination of the biogenic fraction in $\mathrm{CO}_{2}$ in stacks gas using the balance method. International Organization for Standardization, https://www.iso. org/standard/62513.html, 25 pages.

Jones, F.C., Blomqvist, E.W., Bisaillon, M., Lindberg, D.K., Hupa, M., 2013. Determination of fossil carbon content in Swedish waste fuel by four different methods. Waste Manage. Res. 31, 1052-1061.

Kost, T., 2001. Brennstofftechnische Charakterisierung von Haushaltsabfällen ("Fuel Characterization of Household Waste") (Ph.D.Thesis). Dresden Technical University, Dresden, Germany, 134 pages.

Lorber, K.E., Sarc, R., Aldrian, A., 2012. Design and quality assurance for solid recovered fuel. Waste Manage Res 30, 370-380.

Meraz, L., Domínguez, A., Kornhauser, I., Rojas, F., 2003. A thermochemical concept-based equation to estimate waste combustion enthalpy from elemental composition $₫$. Fuel 82, 1499-1507.

Mohn, J., Szidat, S., Fellner, J., Rechberger, H., Quartier, R., Buchmann, B., Emmenegger, L., 2008. Determination of biogenic and fossil $\mathrm{CO}_{2}$ emitted by waste incineration based on ${ }^{14} \mathrm{CO}_{2}$ and mass balances. Bioresource Technol 99, 6471-6479.

Nasrullah, M., Vainikka, P., Hannula, J., Hurme, M., Karki, J., 2014a. Mass, energy and material balances of SRF production process. Part 1: SRF produced from commercial and industrial waste. Waste Manage 34, 1398-1407.

Nasrullah, M., Vainikka, P., Hannula, J., Hurme, M., Karki, J., 2014 b. Mass, energy and material balances of SRF production process. Part 2: SRF produced from construction and demolition waste. Waste Manage 34, 2163-2170.
Nasrullah, M., Vainikka, P., Hannula, J., Hurme, M., Kärki, J., 2015. Mass, energy and material balances of SRF production process. Part 3: Solid recovered fuel produced from municipal solid waste. Waste Manage Res 33, 146-156.

Pomberger, R., Sarc, R., 2014. Use of Solid Recovered Fuels in the Cement Industry. Waste Manage 4, 472-487.

Sarc, R., Lorber, K., Pomberger, R., Rogetzer, M., Sipple, E., 2014. Design, quality, and quality assurance of solid recovered fuels for the substitution of fossil feedstock in the cement industry. Waste Manage Res 32, 565-585.

Schwarzböck, T., Aschenbrenner, P., Rechberger, H., Brandstätter, C., Fellner, J., 2016a. Effects of sample preparation on the accuracy of biomass content determination for refuse derived fuels. Fuel Process Technol 153, 101-110.

Schwarzböck, T., Eygen, E.V., Rechberger, H., Fellner, J., 2017. Determining the amount of waste plastics in the feed of Austrian waste-to-energy facilities. Waste Manage Res 35, 207-216.

Schwarzböck, T., Spacek, S., Aschenbrenner, P., Szidat, S., Eßmeister, J., Fellner, J., 2016b. A new method to determine the biomass content in RDF - practical application and comparison to standardized methods, ISWA World Congress 2016, 19.-21.September 2016; International Solid Waste Association, Novi Sad, Serbia.

Schwarzböck, T., Rechberger, H., Aschenbrenner, P., Spacek, S., Szidat, S., Fellner, J., 2018. Klimarelevanz von Ersatzbrennstoffen - Anwendung und Vergleich verschiedener Bestimmungsmethoden („Climate-relevance of refuse-derived fuels - Application and comparison of different determination methods"). Österr Wasser- und Abfallw 70, 179-193; Springer Vienna; https://doi.org/10.1007/ s00506-018-0466-8.

Staber, W., Flamme, S., Fellner, J., 2008. Methods for determining the biomass content of waste. Waste Manage Res 26, 78-87.

Szidat, S., Salazar, G.A., Vogel, E., Battaglia, M., Wacker, L., Synal, H.-A., Türler, A., 2014. ${ }^{14} \mathrm{C}$ Analysis and Sample Preparation at the New Bern Laboratory for the Analysis of Radiocarbon with AMS (LARA). Radiocarbon 56, 561-566.

VÖZ, 2015, Emissionen aus Anlagen der österreichischen Zementindustrie ("Emissions from Austrias cement industry") - Berichtsjahr 2014, Mauschitz, G., Verein der österreichischen Zementindustrie VÖZ (Association of Austrian cement industry), Vienna, Austria, 29 pages. 